\title{
ZEB1 and ZEB2 gene editing mediated by CRISPR/Cas9 in A549 cell line
}

\author{
Mohammadinejad R ${ }^{1}$, Sassan $\mathrm{H}^{2}$, Pardakhty $\mathrm{A}^{1}$, Hashemabadi $\mathrm{M}^{2}$, Ashrafizadeh $\mathrm{M}^{3}$, \\ Dehshahri $\mathrm{A}^{4}$, Mandegary $\mathrm{A}^{1}$
}

Pharmaceutics Research Center, Institute of Neuropharmacology, Kerman University of Medical Sciences, Kerman, Iran. alimandegary@kmu.ac.ir

\begin{abstract}
OBJECTIVES: One of the best approaches for recognition of protein function is the induction of mutations for a gene knockout. In line with this strategy, gene editing tools allow researchers to induce these mutations. Lung cancer is one of the leading causes of death worldwide. ZEB1 and ZEB2 genes are the candidates for this disease.

METHODS: The ZEB1 and ZEB2 knockout in the non-small cell lung cancer cell line (A549 cell) was investigated. Purification of recombination plasmids was performed from bacteria and then was transported to the A549 cell line. The deletion of ZEB1 and ZEB2 were examined by PCR.

RESULTS: The results demonstrated the mutation and deletion in ZEB1 and ZEB2 genes. Based on the findings of this study, A549 cells were transfected with the vectors carrying the sgRNA/Cas9, simultaneously. The DNA fragment demonstrated the presence of indels in target sites as well as provided the potential of CRISPR/Cas9 system.

CONCLUSION: CRISPR/Cas9 offers a great potential as an efficient technique for editing of ZEB1 and ZEB2 genes in A549 cell line (Tab. 1, Fig. 6, Ref. 44). Text in PDF www.elis.sk.

KEY WORDS: CRISPR/Cas9, gene editing, ZEB1, ZEB2, lung cancer, A549.
\end{abstract}

\section{Introduction}

Based on the high malignancy of lung cancer and due to the low survival rate of patients with lung cancer, much attention has been made towards the treatment of this disorder. Non-small cell lung cancer (NSCLC) is the most common form of lung cancer and surgery is considered the best option for treatment of lung cancer. However, physicians still have troubles in treatment of NSCLC and it seems that gene therapy can provide the major contribution in treatment of NSCLC (1).

Epithelial-mesenchymal transition (EMT) occurs in physiological conditions such as: embryonic development and wound healing. During this process, epithelial cells undergo a number of biochemical and molecular changes to acquire mesenchymal cell traits (2). Upon EMT, the epithelial cells acquire the properties of mesenchymal cells such as: invasiveness, migration, high concentration of extracellular matrix constituents and increased

${ }^{1}$ Pharmaceutics Research Center, Institute of Neuropharmacology, Kerman University of Medical Sciences, Kerman, Iran, ${ }^{2}$ Department of Biology, Faculty of Sciences, Shahid Bahonar University, Kerman, Iran, ${ }^{3}$ Department of basic science, Faculty of veterinary medicine, University of Tabriz, Tabriz, Iran, and ${ }^{4}$ Department of Pharmaceutical Biotechnology, School of Pharmacy, Shiraz University of Medical Sciences, Shiraz, Iran

Address for correspondence: A. Mandegary, Pharmaceutics Research Center, Institute of Neuropharmacology, Kerman University of Medical Sciences, Kerman, Iran, PO Box, 76175-493, Iran.

Phone: +98.34.31325011, Fax: +98.34.31325003 resistance to apoptosis (3). Tumor cells apply EMT for invasion and metastasis $(4,5)$. Li et al examined the effect of EMT in metastasis promotion of pancreatic ductal adenocarcinoma (PDAC) (6). It was found that knockdown of FOXO3a or SPRY2 stimulates EMT and subsequently, enhances the migration and invasion of PDAC cells. Kim et al investigated the effect of EMT in colorectal cancer (CRC) (7). It was shown that a loss of claudin-1 was associated with higher metastatic activity of CRC cells through induction of EMT.

Multiple studies demonstrated the role of zinc finger E-boxbinding homeobox (ZEB) family on invasive behavior of lung cancer cells. The ZEB family consists of two major members: ZEB1 and ZEB2. Zinc fingers are among the most common DNA-binding motifs in eukaryotes. The studies demonstrated the vital role of ZEB proteins in renal development during embryogenesis (8-10). ZEB1 and ZEB2 are related to the limb development and Mowat-Wilson syndrome, respectively $(11,12)$. It has been shown that ZEB1 and ZEB2 can stimulate EMT, so that they negatively affect the expression of E-cadherin via binding to the E-box sequence on the E-cadherin promoter and lack of E-cadherin is associated with EMT induction (13). Harb et al examined the significance of ZEB1 in renal cell carcinoma (14). It was found that positive expression of ZEB1 is associated with a negative E-cadherin expression, EMT induction and metastasis. Ang et al indicated the relationship between expression of ZEB family and invasiveness of breast cancer (15). In the study, it was found that upregulated microRNA-138-5p exerted inhibitory ef- 
Tab. 1. Oligoes for sgRNA construction and primers for mutation confirmation.

\begin{tabular}{|c|c|c|c|}
\hline & Oligoes & SgRNAs & $\begin{array}{c}\text { Target } \\
\text { position }\end{array}$ \\
\hline $\begin{array}{l}\text { W1 } \\
\text { K1 } \\
\text { W21 } \\
\text { K21 } \\
\text { W22 } \\
\text { K22 }\end{array}$ & $\begin{array}{l}\text { caccgCTCTGGGATGCGAAACGCG } \\
\text { aaacCGCGTTTCGCATCCCAGAGC } \\
\text { caccgCACGCGCCACCTATCTTTG } \\
\text { aaacCAAAGATAGGTGGCGCGTGC } \\
\text { caccGTCTCCGCAAACGCTTTAG } \\
\text { aaacCTAAAGCGTTTGCGGAGAC }\end{array}$ & $\begin{array}{l}\text { SgRNA-ZEB1 } \\
\text { SgRNA1-ZEB2 } \\
\text { SgRNA2-ZEB2 }\end{array}$ & \\
\hline & Primers & $\begin{array}{l}\text { Target } \\
\text { gene }\end{array}$ & $\begin{array}{c}\text { Length } \\
\text { (bp) }\end{array}$ \\
\hline $\begin{array}{l}\mathrm{F} \\
\mathrm{R} \\
\mathrm{F} \\
\mathrm{R}\end{array}$ & $\begin{array}{l}\text { ACACGTACATTTCGGACCGA } \\
\text { CCTATGCTCCACTCCTTGCT } \\
\text { GGGAGGGAGGTGGAATTTCA } \\
\text { TCCCGGAGCAAACTGTACAA }\end{array}$ & ZEB2 & 365 \\
\hline & Primers for colony PCR & \multicolumn{2}{|c|}{ Length(bp) } \\
\hline $\begin{array}{l}F(v) \\
R(v) \\
F(v) \\
K \\
W \\
R(v)\end{array}$ & $\begin{array}{l}\text { GGGCCTATTTCCCATGATTCCT } \\
\text { CGCGCTAAAAACGGACTAGC } \\
\text { GGGCCTATTTCCCATGATTCCT } \\
\text { K } \\
\text { W } \\
\text { CGCGCTAAAAACGGACTAGC }\end{array}$ & $\begin{array}{l}402 \\
280\end{array}$ & \\
\hline
\end{tabular}

fect on ZEB2 to prevent proliferation, metastasis and EMT of lung adenocarcinoma cells (16).

The focus on gene manipulation is due to the failure of drugs in cancer therapy. Clustered Regularly Interspaced Short Palindromic Repeats (CRISPR) (17) is a based genomic editing technology, which has attracted much attention due to its high efficacy, ease of use and great multi-targeting (18-20). CRISPR/Cas actually is a part of adaptive immune system defense of bacteria, which functions in three distinct steps: adaptation, expression and interference. The aim of this system is to inhibit the invasion of viruses and phages. There are three major types of CRSPR/Cas including types I, II and III and bacterial type II CRISPR/Cas is extensively used. CRISPR/Cas system consists of a Cas endonuclease, a CRISPR RNA (crRNA) and a trans-activating crRNA (tracrRNA). CrRNA and tracrRNA form a single guide RNA (sgRNA). SgRNA targets DNA and subsequently, produces double-strand break (DSB). Cell uses two systems to repair this break: non-homologous end joining (NHEJ) and homology directed repair (HDR). NHEJ is based on insertion/deletion and frameshift mutation in target DNA, whereas HDR provides a template DNA for homologous recombination (21). It has been suggested that CRISPR is beneficial for basic and clinical trial studies and also treatment of disorders associated with mutations. The main purpose of the present study was to investigate the possibility of ZEB1 and ZEB2 gene editing in the NSCLC cells. The major note of this study is the preparation of appropriate sgRNA, which was able to target ZEB1 and ZEB2 genes. In this research, the guides were successfully tried on A549 cells, which had the high capability to edit the genes.

\section{Materials and methods}

Preparation of sgRNA

The specific oligonucleotides for targeting favorite region of ZEB1 and ZEB2 genes were designed by online CRISPR De- sign Tool (http://crispr.mit.edu/) and oligoes for construction of sgRNA-ZEB1, sgRNA1-ZEB2 and sgRNA2-ZEB2 are listed in the Table 1. To prepare each of the gRNA related genes, $3 \mu 1$ of each top and bottom strands were suspended at final concentration of $100 \mu \mathrm{M}, 4 \mu \mathrm{l} \mathrm{NaCl} 0.5 \mathrm{M}, 4 \mu 1$ ligation buffer and water was added up to $20 \mu \mathrm{l}$ volume. Annealing process was done using the following parameters: $95^{\circ} \mathrm{C}$ for $5 \mathrm{~min}$; ramp down to $25^{\circ} \mathrm{C}$ at $5{ }^{\circ} \mathrm{C} \mathrm{min}^{-1}$.

\section{Cloning sgRNA and plasmid construction}

Annealed oligoes related to sgRNA-ZEB1, sgRNA1-ZEB2 and sgRNA2-ZEB2 were diluted $1: 100$ by adding $1 \mu 1$ of annealed oligoes to $99 \mu \mathrm{l}$ of $d d H 2 O$ and sgRNA fragment was ligated in linear pSpCas9 (BB)-2A-Puro (PX459) V2.0 vector, which was digested by Bbs1 enzyme. Colony PCR for recombinant vector confirmation was performed using sgRNAs oligoes as primer and specific primers vector, which is listed in Table 1.

\section{Cell line and culture}

NSCLC cell line (A549) was purchased from the National Cell Bank of Iran, Pasteur Institute of Iran and then, cultured in Dulbecco's Modified Eagle Medium (DMEM) supplemented with FBS $(10 \%, \mathrm{v} / \mathrm{v})$ and antibiotics [penicillin (100 units $/ \mathrm{mL})$ and streptomycin $(100 \mu \mathrm{g} / \mathrm{mL})]$ at $37^{\circ} \mathrm{C}$ in a $\mathrm{CO}_{2}$ incubator $\left(5 \% \mathrm{CO}_{2}\right.$ and $95 \%$ relative humidity).

\section{Cell transfection}

A549 cells $(6 \times 105)$ at passage 3 or 4 (after thawing of the cells) were seeded as single colonies in 12 -well plates. After suitable cell density, recombinant vectors were transfected. Two days after transfection, the transfected cells were treated with $2 \mu \mathrm{g} / \mathrm{ml}$ (puromycin-Roche Life Science, Penzberg, Upper Bavaria, Germany) for three days, to remove un-transfected cells and selection of the resistant cells.

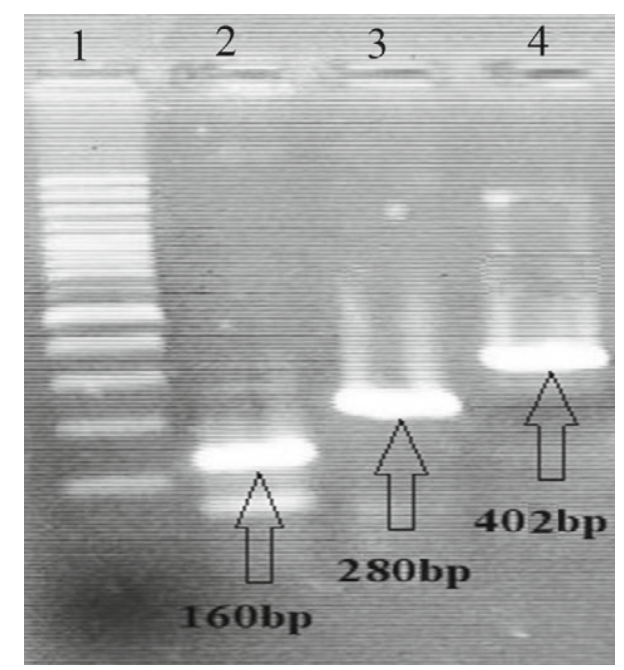

Fig. 1. Results from colony PCR which was performed to confirm the cloning of the guide for ZEB1. 


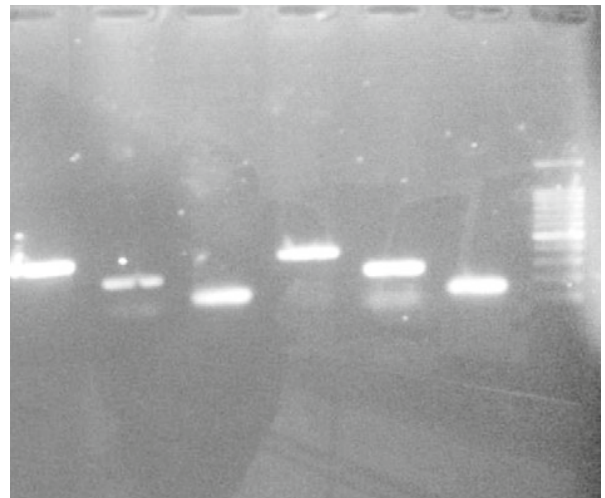

Fig. 2. Results from colony PCR which was performed to confirm the cloning of the guide for ZEB2.

\section{Sequencing analysis and mutation confirmation}

The genomic DNA of the transfected and control cells was isolated. DNA fragments that covered the gRNA target region were amplified using Polymerase Chain Reaction (PCR). Mutation site targeted by sgRNAs were amplified by Pfu DNA Polymerase (Maxcell, Iran). The specific primers are listed in the Table 1.

The PCR products were verified using gel electrophoresis, purified using the QIAquick gel extraction kit (Quiagen, Hilden Germany), and directly sequenced to scan mutations induced by Cas9 endonuclease.

\section{Results}

Cloning results

SgRNAs cloning in px459 vector were confirmed using colony PCR technique (Figs 1 and 2) and vector sequencing with certain external segment was done by Macrogen Company and the sequencing analysis approved the presence of specific sgRNA in vectors.

\section{Knockout genes by CRISPR/Cas9 in A549 cells}

To knockout ZEB1 and ZEB2 genes, three sgRNAs targeting human genes were selected: one target ZEB1 and two targets ZEB2 genes. The target sequence is shown in Figures 3 and 4. A549 cells were transfected with the vectors carrying the sgRNA/ Cas9, simultaneously, scrambled transfected cells were kept as control. Treatment with puromycin antibiotic was adopted in order to choose transfected cells.

\section{Insertion/deletion (indel) scanning}

To evaluate indel produced by CRISPR/Cas9 system, A549 cells were transfected with the sgRNA. Un-transfected cells were removed by puromycin treatment, genomic DNA was extracted, and genomic regions containing sgRNA target sites were amplified. The DNA fragment exhibited the presence of indels in target sites as well as provided the potential of CRISPR/Cas9 system (Figs 5 and 6). Also, sequencing analysis demonstrated a mutation in specific region of ZEB1 and ZEB2.

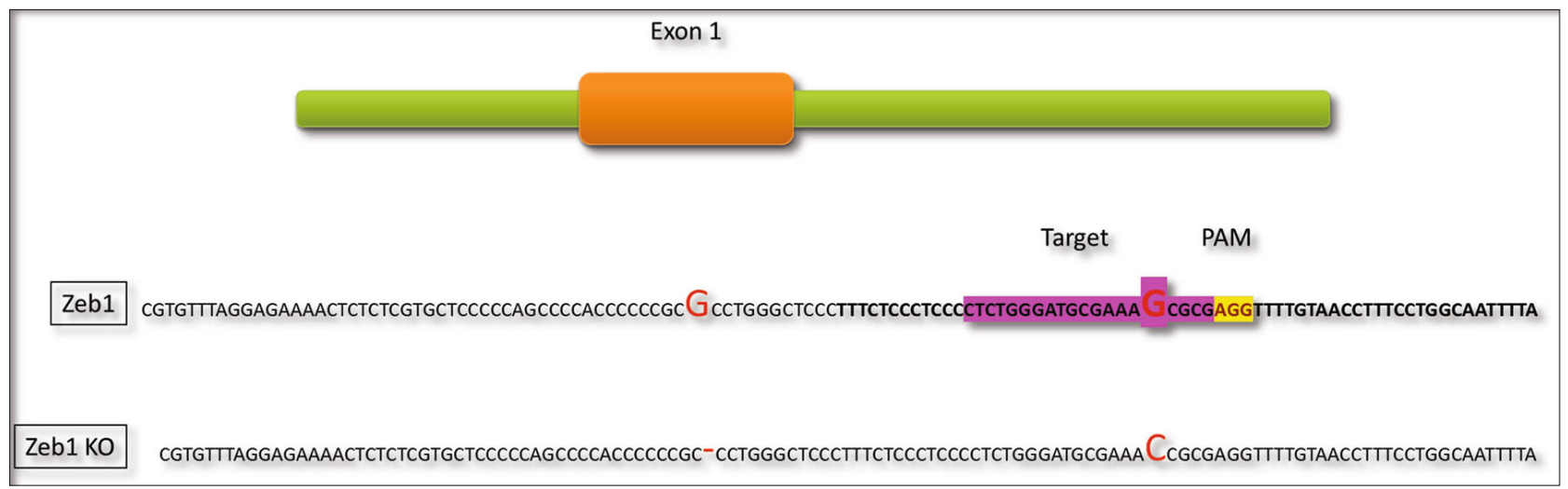

Fig. 3. Schematic illustration of ZEB1 gene structure and sequences around the target loci.

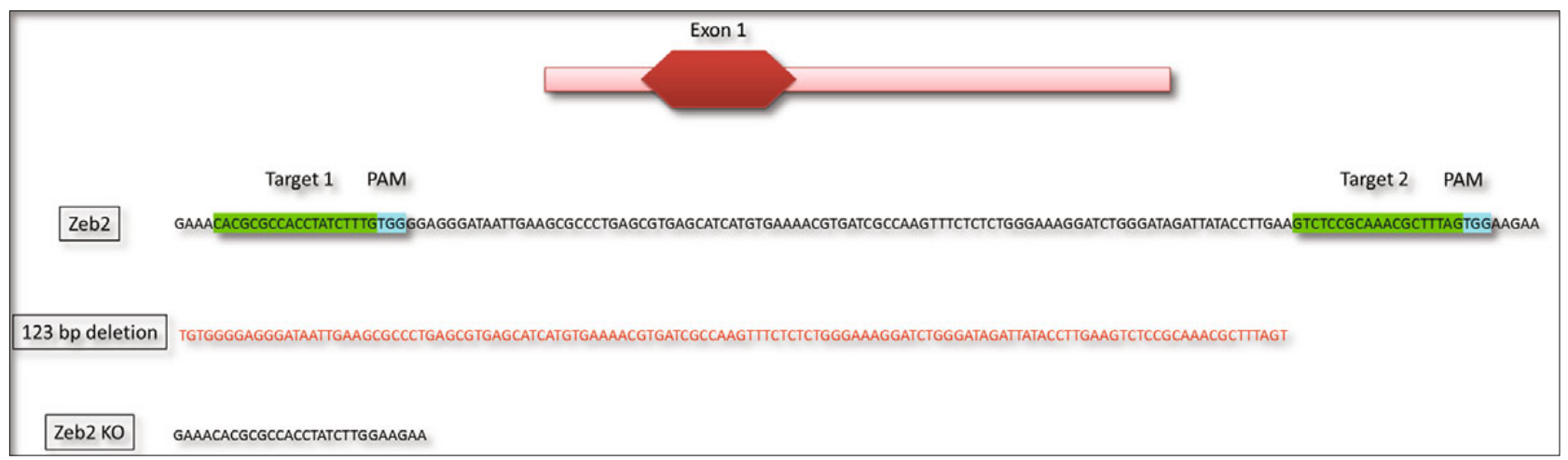

Fig. 4. Schematic illustration of ZEB2 gene structure and sequences around the target loci. 


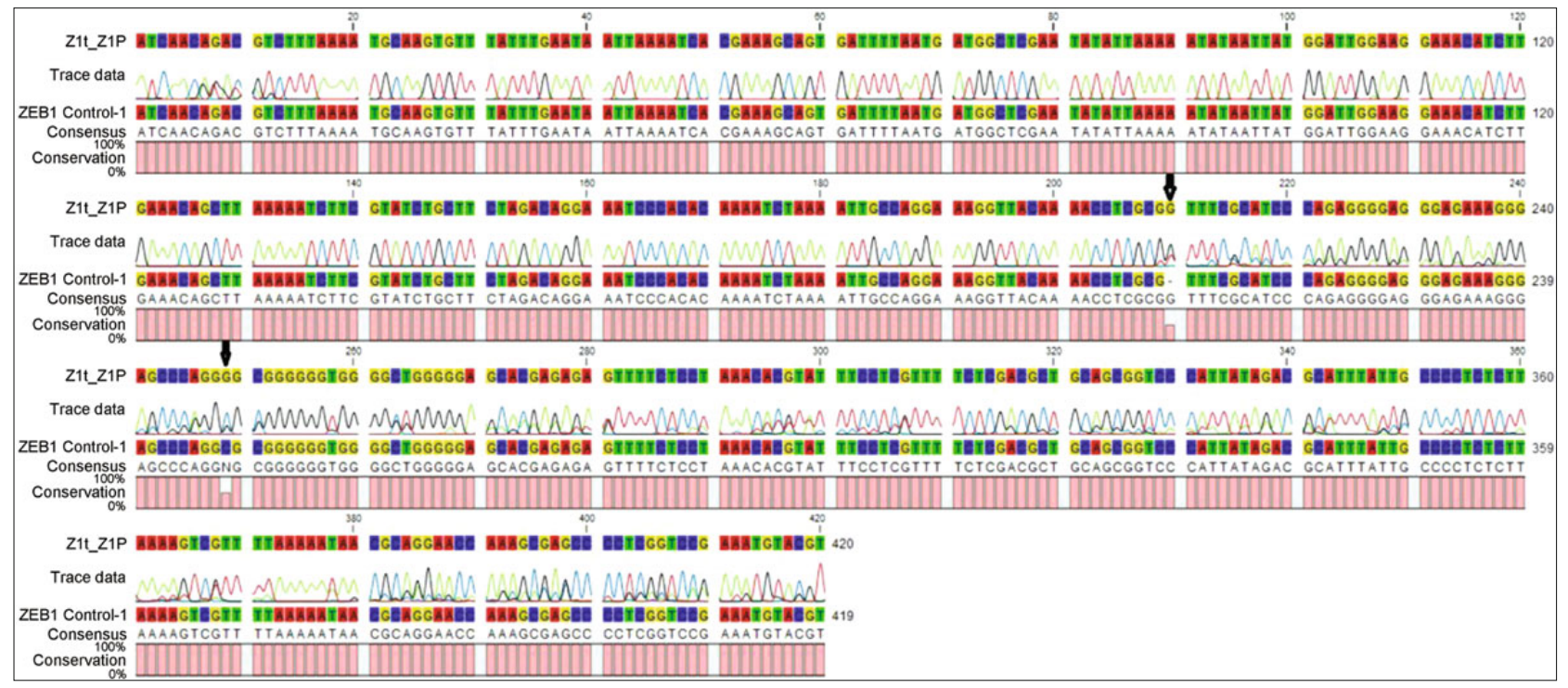

Fig. 5. Results from PCR to confirm mutation in the ZEB1 gene.

\section{Discussion}

Cancer is one of the most challenging disorders around the world (22-25) and it appears that lung has a particular sensitivity to potentially toxic agents and damage, resulting in various lung disorders (26-29). Gene therapy is considered a promising strategy in promoting the health of a number of inherited and acquired human conditions such as: cancer, diabetes, cardiovascular diseases and mental disorders (30). During the recent years, CRISPR/Cas9 has shown a potential efficacy for genome editing (31). Compared to the conventional gene editing systems such as: zinc-finger nuclease (ZNF) and transcription-activator-like effector nuclease (TALEN), type II CRISPR is more efficient, flexible and less costly (32). It is possible to simultaneously edit various genes through loading several sgRNAs into a single CRISPR assay. Overexpression of ZEB1 is often associated with EMT induction and more invasive growth of cancer cells. Several studies examined the role of ZEB1 in the invasion of tumor cells and the results were interesting. In the study, Maturi et al examined the impact of ZEB1 knockout in triple negative breast cancer cells (33). It was found that ZEB1 was not only involved in the EMT induction in breast cancer cells, but it also contributed to the oncogenic potential of these cancer cells. In another study, the role of ZEB1 in the bortezomib sensitivity of mantle cell lymphoma was evaluated (34). It was shown that ZEB1 knockdown led to the higher sensitivity of mantle cell lymphoma to bortezomib. Zhang et al indicated the expression of ZEB1 in non-neoplastic Barret's cells (35). It was found that these cells had enhanced levels of ZEB1 and showed some of the properties of EMT including reduced cadherin 1, elevated fibronectin 1 , vimentin and matrix metalloproteinase 2 , and enhanced motility. Jagle et al demonstrated the role of ZEB1 in invasiveness of LS174T colorectal cancer cells (36). Notably, it was shown that ectopic ZEB1 was associated with potential impacts on the cell

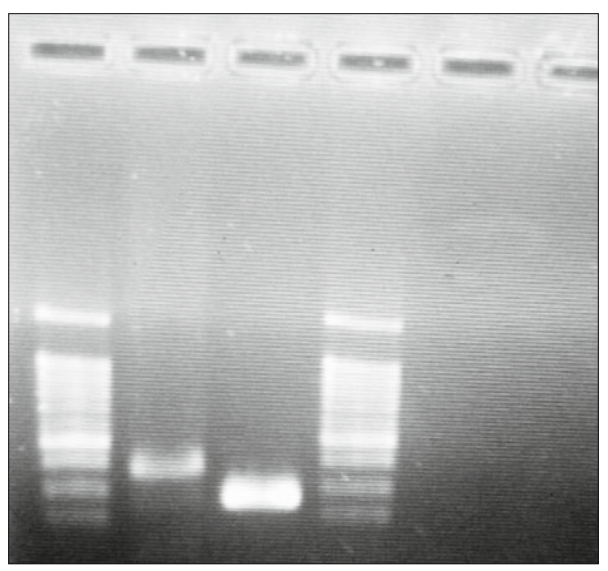

Fig. 6. Results from PCR to confirm mutation in the ZEB2 gene.

morphology and invasive growth and also expression of ZEB1 did not result in an inhibition of epithelial marker genes and upregulation of mesenchymal markers. On the other hand, Hosain et al demonstrated the role of ZEB1 in colon cancer cells (37). It was found that stimulation of EMT in the tumor cells exposed to doxorubicin was mainly performed via ZEB1 factor, showing the potential role of this factor in the invasive growth of colon cancer cells. The role of EMT in NSCLC is important due to its effect on the prognosis. Yang et al evaluated the impact of FOXP3 on EMT in NSCLC patients (38). It was found that FOXP3 decreased the level of E-cadherin and increased the level of N-cadherin to stimulate EMT, resulting in enhancing tumor growth, metastasis and decrease in overall survival. In another study, Liu et al examined the effect of hepatocyte growth factor (HGF) on EMT in NSCLC (15). It was shown that HGF stimulated EMT in NSCLC cell liners A549 and H460 to enhance the cellular migration and 
invasion. These studies demonstrated the negative effect of EMT in the prognosis of patients with NSCLC and due to the remarkable role of ZEB1 in EMT, it would be effective in improving survival and prognosis by knock-outing this gene. In this study, we demonstrated that CRISPR/Cas9 system was a valuable, efficient and inexpensive tool for ZEB1-knockout, which can be used for generation of animal models and investigating the effects of therapeutic compounds.

In the study, Lee and colleagues examined the role of Bcl2-interacting cell death suppressor (BIS) in the migration and invasion of A549 NSCLC (39). The results of this study showed that BIS knockout by CRISPR/Cas9 led to the inhibition of migration and invasion of A549 cells. Also, CRISPR/Cas9 has revealed the role of other transcription factors such as: UTX and Rsf-1 in lung tumorigenesis and drug sensitivity, respectively (40, 41). Hence, CRISPR/Cas9 is an efficient system for discovering the role of genes in lung cancer. In this study, we focused on the role of ZEB2 gene in the invasion and malignancy of A459 cells via using CRISPR. The common structural property of ZEB2 is the presence of a homeodomain with two clusters of zinc finger (42). This protein has a full-length of 1215 amino acids in the mouse and 1214 aminoacids in human (43). Developmentally, ZEB2 plays a remarkable role in various cellular mechanisms including embryonic development (43). Over the past decades, much attention has been performed towards the role of ZEB2 in the malignancy and invasion of different cancers. In the study, the effect of FAT10 on the invasion and migration of breast cancer cells was evaluated (21). The results demonstrated that FAT10 bound to the ZEB2 to diminished its ubiquition, resulting in upregulation of ZEB2 and invasion and metastasis of breast cancer cells. Hong and coworkers examined the effect of miR-124 on the invasion and metastasis of triple-negative breast cancer (TNBC) (44). It was found that miR-124 underwent downregulation in TNBC cells and tissues and overexpression of miR-124 prevented the proliferation, metastasis and EMT of TNBC cells through inhibition of ZEB2. These studies demonstrated the vital role of ZEB2 in the activation of tumor cells. In this study, we edited ZEB1 and ZEB2 genes using CRISPR/Cas9 and this might result in suppression of ZEB1 and ZEB2 and decreased malignancy of A549 cells and might be associated with a better prognosis in patients with NSCLC.

\section{Conclusion}

The major note of this study was the preparation of appropriate guide, which was able to target ZEB1 and ZEB2 genes. In this research, the guides were successfully tried on A549 cells, which had a high capability of cutting and the section containing promoter was removed from some of the cells. On the other hand, due to the association of ZEB1 and ZEB2 proteins with EMT markers, it could be concluded that inactivation of ZEB1 and ZEB2 proteins led to the lack of EMT stimulation. Generation of animal disease models is the major suggestion of this study to perform treatment procedures and find protein functions as well as to design the function network of proteins using CRISPR/Cas9 system.

\section{References}

1. Herbst RS, Morgensztern D, Boshoff C. The biology and management of non-small cell lung cancer. Nature 2018; 553 (7689): 446.

2. Nisticò P, Bissell MJ, Radisky DC. Epithelial-mesenchymal transition: general principles and pathological relevance with special emphasis on the role of matrix metalloproteinases. Cold Spring Harbor Persp Biol 2012; 4 (2): a011908.

3. Salehi B, Zucca P, Sharifi-Rad M, Pezzani R, Rajabi S, Setzer WN et al. Phytotherapeutics in cancer invasion and metastasis. Phytother Res 2018.

4. Polyak K, Weinberg RA. Transitions between epithelial and mesenchymal states: acquisition of malignant and stem cell traits. Nature Rev Cancer 2009; 9 (4): 265.

5. Dongre A, Weinberg RA. New insights into the mechanisms of epithelial-mesenchymal transition and implications for cancer. Nature Rev Mol Cell Biol 2018: 1.

6. Li J, Yang R, Dong Y, Chen M, Wang Y, Wang G. Knockdown of FOXO3a induces epithelial-mesenchymal transition and promotes metastasis of pancreatic ductal adenocarcinoma by activation of the $\beta$-catenin/ TCF4 pathway through SPRY2. J Exp Clin Cancer Res 2019; 38 (1): 38.

7. Kim NY, Pyo JS, Kang DW, Yoo SM. Loss of claudin-1 expression induces epithelial-mesenchymal transition through nuclear factor-kB activation in colorectal cancer. Pathol Res Practice 2019.

8. Darling DS, Stearman RP, Qi Y, Qiu M-S, Feller JP. Expression of $Z$ fhep $/ \delta E F 1$ protein in palate, neural progenitors, and differentiated neurons. Gene Expres Patterns 2003; 3 (6): 709-717.

9. Takagi T, Moribe H, Kondoh H, Higashi Y. DeltaEF1, a zinc finger and homeodomain transcription factor, is required for skeleton patterning in multiple lineages. Development 1998; 125 (1): 21-31.

10. Yen G, Croci A, Dowling A, Zhang S, Zoeller RT, Darling DS. Developmental and functional evidence of a role for Zfhep in neural cell development. Mol Brain Res 2001; 96 (1-2): 59-67.

11. Dastot-Le Moal F, Wilson M, Mowat D, Collot N, Niel F, Goossens M. ZFHX1B mutations in patients with Mowat-Wilson syndrome. Human Mutat 2007; 28 (4): 313-321.

12. Moribe H, Takagi T, Kondoh H, Higashi Y. Suppression of polydactyly of the Gli3 mutant (extra toes) by $\delta \mathrm{EF} 1$ homozygous mutation. Develop Growth Different 2000; 42 (4): 367-376.

13. Gonzalez DM, Medici D. Signaling mechanisms of the epithelialmesenchymal transition. Sci Signal 2014; 7 (344): re8-re.

14. Harb OA, Elfeky MA, El Shafaay BS, Taha HF, Osman G, Harera IS et al. SPOP, ZEB-1 and E-cadherin expression in clear cell renal cell carcinoma (cc-RCC): Clinicopathological and prognostic significance. Pathophysiol 2018.

15. Liu F, Song S, Yi Z, Zhang M, Li J, Yang F et al. HGF induces EMT in non-small-cell lung cancer through the hBVR pathway. Eur J Pharmacol 2017; 811: 180-190.

16. Zhu D, Gu L, Li Z, Jin W, Lu Q, Ren T. MiR-138-5p suppresses lung adenocarcinoma cell epithelial-mesenchymal transition, proliferation and metastasis by targeting ZEB2. Pathol Res Practice 2019.

17. Khadempar S, Familghadakchi S, Motlagh RA, Farahani N, Dashtiahangar M, Rezaei $\mathbf{H}$ et al. CRISPR-Cas9 in genome editing: Its function and medical applications. J Cell Physiol 2019; 234 (5): $5751-5761$. 
18. Karimian A, Azizian K, Parsian H, Rafieian S, Shafiei-Irannejad V, Kheyrollah M et al. CRISPR/Cas9 technology as a potent molecular tool for gene therapy. J Cell Physiol.

19. Khan MHU, Khan SU, Muhammad A, Hu L, Yang Y, Fan C. Induced mutation and epigenetics modification in plants for crop improvement by targeting CRISPR/Cas9 technology. J Cell Physiol 2018; 233 (6): 4578-4594.

20. Norouzi-Barough L, Sarookhani M, Salehi R, Sharifi M, Moghbelinejad S. CRISPR/Cas9, a new approach to successful knockdown of $\mathrm{ABCB} 1 / \mathrm{P}$-glycoprotein and reversal of chemosensitivity in human epithelial ovarian cancer cell line. Iranian journal of basic medical sciences 2018; 21 (2): 181.

21. Zou Y, Ouyang Q, Wei W, Yang S, Zhang Y, Yang W. FAT10 promotes the invasion and migration of breast cancer cell through stabilization of ZEB2. Biochem Biophys Res Commun 2018; 506 (3): 563-570.

22. Ashrafizadeh M, Mohammadinejad R, Tavakol S, Ahmadi Z, Roomiani S, Katebi M. Autophagy, anoikis, ferroptosis, necroptosis, and endoplasmic reticulum stress: Potential applications in melanoma therapy. J Cell Physiol 2019.

23. Mohammadinejad R, Ahmadi Z, Tavakol S, Ashrafizadeh M. Berberine as a potential autophagy modulator. J Cell Physiol 2019; 234 (9): 14914-14926.

24. Ahmadi Z, Mohammadinejad R, Ashrafizadeh M. Drug delivery systems for resveratrol, a non-flavonoid polyphenol: Emerging evidence in last decades. J Drug Deliv Sci Technol 2019; 51: 591-604.

25. Ashrafizadeh M, Ahmadi Z, Mohammadinejad R, Kaviyani N, Tavakol S. Monoterpenes modulating autophagy: A review study. Basic Clin Pharmacol Toxicol 2019.

26. Rasooli R, Pourgholamhosein F, Kamali Y, Nabipour F, Mandegary A. Combination therapy with pirfenidone plus prednisolone ameliorates paraquat-induced pulmonary fibrosis. Inflammation 2018; 41 (1): 134-142.

27. Samareh Fekri M, Poursalehi HR, Sharififar F, Mandegary A, Rostamzadeh F, Mahmoodi R. The effects of methanolic extract of Glycyrrhiza glabra on the prevention and treatment of bleomycin-induced pulmonary fibrosis in rat: experimental study. Drug Chem Toxicol 2019: 1-7.

28. Samareh Fekri M, Mandegary A, Sharififar F, Poursalehi HR, Nematollahi MH, Izadi A et al. Protective effect of standardized extract of Myrtus communis L. (myrtle) on experimentally bleomycin-induced pulmonary fibrosis: biochemical and histopathological study. Drug Chem Toxicol 2018; 41 (4): 408-414.

29. Pourgholamhossein F, Rasooli R, Pournamdari M, Pourgholi L, Samareh-Fekri M, Ghazi-Khansari M et al. Pirfenidone protects against paraquat-induced lung injury and fibrosis in mice by modulation of inflammation, oxidative stress, and gene expression. Food Chem Toxicol 2018; 112: 39-46.

30. Mohammadinejad R, Dadashzadeh A, Moghassemi S, Ashrafizadeh M, Dehshahri A, Pardakhty A et al. Shedding light on gene therapy: carbon dots for the minimally invasive image-guided delivery of plasmids and noncoding RNAs. J Adv Res 2019; 18: 81-93.

31. Dunbar CE, High KA, Joung JK, Kohn DB, Ozawa K, Sadelain M. Gene therapy comes of age. Science 2018; 359 (6372): eaan4672.
32. Gaj T, Gersbach CA, Barbas III CF. ZFN, TALEN, and CRISPR/ Cas-based methods for genome engineering. Trends Biotechnol 2013; 31 (7): 397-405

33. Maturi V, Enroth S, Heldin CH, Moustakas A. Genome-wide binding of transcription factor ZEB1 in triple-negative breast cancer cells. J Cell Physiol 2018.

34. Luanpitpong S, Poohadsuan J, Samart P, Kiratipaiboon C, Rojanasakul Y, Issaragrisil S. Reactive oxygen species mediate cancer stemlike cells and determine bortezomib sensitivity via Mcl-1 and Zeb-1 in mantle cell lymphoma. Biochim Biophys Acta (BBA) - Mol Basis Dis 2018; 1864 (11): 3739-3753.

35. Zhang Q, Agoston AT, Pham TH, Zhang W, Zhang X, Huo X et al. Acidic Bile Salts Induce Epithelial to Mesenchymal Transition via VEGF Signaling in Non-Neoplastic Barrett's Cells. Gastroenterol 2019; 156 (1): 130-144. e10.

36. Jägle S, Dertmann A, Schrempp M, Hecht A. ZEB1 is neither sufficient nor required for epithelial-mesenchymal transition in LS174T colorectal cancer cells. Biochem Biophys Res Comm 2017; 482 (4): 1226-1232.

37. Hosain SB, Khiste SK, Uddin MB, Vorubindi V, Ingram C, Zhang $S$ et al. Inhibition of glucosylceramide synthase eliminates the oncogenic function of p53 R273H mutant in the epithelial-mesenchymal transition and induced pluripotency of colon cancer cells. Oncotarget 2016; 7 (37): 60575.

38. Yang S, Liu Y, Li M-Y, Ng CS, Yang S-l, Wang S et al. FOXP3 promotes tumor growth and metastasis by activating Wnt/ $\beta$-catenin signaling pathway and EMT in non-small cell lung cancer. Mol Cancer 2017; 16 (1): 124

39. Lee J, Yun HH, Kim S, Ji SH, Kuh H-J, Lee J-H. Implication of BIS in the Migration and Invasion of A549 Non-small Cell Lung Cancer Cells. Anticancer Res 2018; 38 (9): 5057-5065.

40. Wu Q, Tian $\mathrm{Y}$, Zhang J, Tong $\mathrm{X}$, Huang $\mathrm{H}$, Li S et al. In vivo CRISPR screening unveils histone demethylase UTX as an important epigenetic regulator in lung tumorigenesis. Proc Nat Acad Sci 2018; 115 (17): E3978-E86.

41. Chen X, Sun X, Guan J, Gai J, Xing J, Fu L et al. Rsf-1 influences the sensitivity of non-small cell lung cancer to paclitaxel by regulating NF-kB pathway and its downstream proteins. Cell Physiol Biochem 2017; 44 (6): 2322-2336.

42. Srivatsa S, Parthasarathy S, Molnár Z, Tarabykin V. Sip1 downstream Effector ninein controls neocortical axonal growth, ipsilateral branching, and microtubule growth and stability. Neuron 2015; 85 (5): 998-1012.

43. Conidi A, Cazzola S, Beets K, Coddens K, Collart C, Cornelis F et al. Few Smad proteins and many Smad-interacting proteins yield multiple functions and action modes in TGF $\beta /$ BMP signaling in vivo. Cytokine Growth Factor Rev 2011; 22 (5-6): 287-300.

44. Ji H, Sang M, Liu F, Ai N, Geng C. miR-124 regulates EMT based on ZEB2 target to inhibit invasion and metastasis in triple-negative breast cancer. Pathol - Res Practice 2018.

Received May 26, 2019. Accepted July 30, 2019. 